\title{
The Mechanism for HAZ Liquation of Nickel-Based Alloy 617B During Gas Tungsten Arc Welding
}

\author{
Shanlin $\mathrm{Li}^{1,2}$, Kejian Li ${ }^{1,2, *}$, Mengjia $\mathrm{Hu}^{1,2}$, Yao Wu ${ }^{3}$, Zhipeng Cai ${ }^{1,2,4,5, *}$ and Jiluan Pan ${ }^{1,2}$ \\ 1 Department of Mechanical Engineering, Tsinghua University, Beijing 10084, China; \\ shanlinli2015@163.com (S.L.); hmj1078@163.com (M.H.); pjl-dme@mail.tsinghua.edu.cn (J.P.) \\ 2 Key Laboratory for Advanced Materials Processing Technology, Ministry of Education, Beijing 100084, China \\ 3 Tianjin Research Institute for Advanced Equipment, Tsinghua University, Tianjin 300300, China; \\ wuyao_1209@163.com \\ 4 Collaborative Innovation Center of Advanced Nuclear Energy Technology, Tsinghua University, \\ Beijing 10084, China \\ 5 State Key Laboratory of Tribology, Tsinghua University, Beijing 10084, China \\ * Correspondence: kejianli@mail.tsinghua.edu.cn (K.L.); caizhipeng92@outlook.com or \\ czpdme@mail.tsinghua.edu.cn (Z.C.); Tel.: +86-010-62789568 (K.L.); +86-010-62788517 (Z.C.)
}

Received: 26 November 2019; Accepted: 2 January 2020; Published: 6 January 2020

\begin{abstract}
The mechanism for HAZ (heat-affected zone) liquation of alloy 617B during gas tungsten arc welding (GTAW) was investigated. Welding thermal simulation work was conducted to investigate the effects of thermal parameters (peak temperature, holding time, and thermal cycle numbers) on $\mathrm{M}_{23} \mathrm{C}_{6}$ carbides' evolutionary behavior in nickel-based alloy 617B. OM (optical microscopy), SEM (scanning electron microscopy), TEM (transmission electron microscopy), and SIMS (secondary ion mass spectrometry) were employed to characterize HAZ carbides. It was found that the constitutional liquation of $\mathrm{M}_{23} \mathrm{C}_{6}$ carbides is responsible for HAZ liquation in alloy 617B. Rapid heating meant that solute atoms released from partially dissolved $\mathrm{M}_{23} \mathrm{C}_{6}$ carbides did not have enough time to sufficiently diffuse into the matrix, resulting in eutectic reaction $\mathrm{M}_{23} \mathrm{C}_{6}+\gamma \rightarrow$ liquid in the temperature range from $1250{ }^{\circ} \mathrm{C}$ to $1300{ }^{\circ} \mathrm{C}$. In the following cooling process, the liquid phase transformed into $\gamma$ and $\mathrm{M}_{23} \mathrm{C}_{6}$ (or $\mathrm{M}_{6} \mathrm{C}$ ) carbides simultaneously, creating a eutectic microstructure. Subsequent thermal cycles with peak temperature $1100{ }^{\circ} \mathrm{C}$ and proper holding time brought about a tempering effect to precipitate fine $\mathrm{M}_{23} \mathrm{C}_{6}$ carbides from the $\mathrm{Cr}$ supersaturated zone around the eutectic microstructure. Boron was found to be enriched in carbides and was expected to promote HAZ liquation by two mechanisms. No cracking caused by HAZ liquation has been found, indicating that GTAW is a suitable method for joining alloy 617B.
\end{abstract}

Keywords: nickel-based alloys; welding; thermal simulation; constitutional liquation; $\mathrm{M}_{23} \mathrm{C}_{6}$ carbides

\section{Introduction}

Nickel-based alloy 617B, a boron-modified version of the commercial alloy 617, has been widely used in fossil fuel power plants due to its excellent creep and oxidation resistance [1,2]. Welding is a common technique to join nickel-based alloys and other metals such as steels. For nickel-based alloys, welding provides thermal cycles far away from equilibrium, presenting some new metallurgical phenomena such as liquation cracking [3-5], solidification cracking [6-8], and so on. These phenomena lead to a decline in joint performance $[9,10]$. Much work has been conducted by other researchers to clarify the reasons for these phenomena and to eliminate or reduce the cracks resulting from welding.

In terms of liquation cracking in nickel-based alloys, it tends to occur in welding HAZ, where only solid-state phase transformation is supposed to take place. Liquation cracking forms in the presence of 
liquation and thermal tensile stress. During the heating process, some liquid will form, wetting the grain boundaries. If the stress applied to the weld joint exceeds the strength limit of the wet grain boundaries, cracks will form along these grain boundaries. There are two main mechanisms for HAZ liquation, one of which is connected to minor elements, such as B, P, and S. These minor elements tend to segregate at grain boundaries, lowering the melting point [11,12]. Although the temperature is lower than solidus during heating, some liquid will form at the grain boundaries. Nowadays, the amount of $\mathrm{P}+\mathrm{S}$ can be as low as $100 \mathrm{ppm}(0.01 \mathrm{wt} \%)$ by using a special double-melting technique, and at this level, the role of $\mathrm{P}$ and $\mathrm{S}$ in liquation cracking can be negligible. However, the contribution of boron to HAZ liquation cannot be ignored in some alloys, such as alloy $617 \mathrm{~B}$ and 718 plus, because a certain amount of boron has been introduced in these alloys for the purpose of improving creep resistance [13,14]. Except for lowering the melt point of grain boundaries, boron has an ability to promote the liquid phase to spread the grain boundary, thereby promoting the development of HAZ liquation $[15,16]$. The other mechanism for HAZ liquation is constitutional liquation, resulting from eutectic reactions between some large precipitates and the matrix [17]. In nickel-based alloys, the precipitates leading to constitutional liquation can be carbides or intermetallic compounds such as MC [18-20], $\mathrm{M}_{6} \mathrm{C}$ [19], or Laves phase [21]. During the rapid heating provided by welding, there is not enough time for solute atoms released from dissolving precipitates to diffuse into the matrix homogeneously, causing subsequent eutectic reactions between the incompletely dissolved precipitates and the saturated matrix.

Researchers have reported that HAZ liquation occurs in the welding of alloy 617. Wen [3] reported the behavior of grain boundary liquation cracking in fiber laser welding of alloy 617 and found that the degree of liquation cracking decreased when the heating input and preheating temperature increased. Phuraya [22] used a high-temperature confocal laser scanning microscopy to investigate the liquation process of alloy 617 by in situ observation. Meanwhile, $\mathrm{Xu}$ [23] reported that some lamellar structures occurred near the fusion line of alloy 617B welded joint and found that the peak temperature played a key role in the formation of these lamellar structures. Fink and Zinke [24] found that liquation cracking occurred predominantly at or near the fusion line in the welded joint of alloy 617, and interdendritic enrichment of Mo formed at the crack tip. These studies suggest that HAZ liquation might occur in the welded joint of alloy 617B. Studies need to be conducted to verify HAZ liquation and to reveal the liquation mechanism of 617B during welding. In the present work, thermal simulation was applied to reveal the microstructure evolution of HAZ. The influence of peak temperature and the number of thermal cycles on carbides' behavior were performed, and the distribution and effect of boron were also discussed.

\section{Materials and Methods}

Alloy 617B, used in the present work, was provided by ThyssenKrupp VDM ${ }^{\circledR}$ (Plettenberger Straße 2, Werdohl, Germany), and was produced by vacuum induction melting (VIM), electroslag remelting (ESR), hot-rolling, and solution annealing at 1150 for $2 \mathrm{~h}$. The thermal conductivity coefficients at room temperature and $1200{ }^{\circ} \mathrm{C}$ are $11.7 \mathrm{~W} / \mathrm{mK}$ and $32.3 \mathrm{~W} / \mathrm{mK}$, and the melting range of this alloy is about $1330^{\circ} \mathrm{C}$ to $1380{ }^{\circ} \mathrm{C}$ [13]. Two workpieces of alloy $617 \mathrm{~B}$ with a thickness of $50 \mathrm{~mm}$ were joined by the GTAW multi-layer technique. The set-up structure and groove are shown in Figure 1a,b. A filler metal (ERNiCrCoMo-1) was selected to obtain a matched creep rupture strength with the 617B base metal (BM). The chemical compositions of the as-received 617B and the filler metal are listed in Table 1. The detailed welding parameters are shown in Table 2. A transverse section, containing BM, HAZ, and WM (weld metal), as shown in Figure 1c, was cut from the welded joint by electrodischarge machining for microstructural investigation. 
(a)

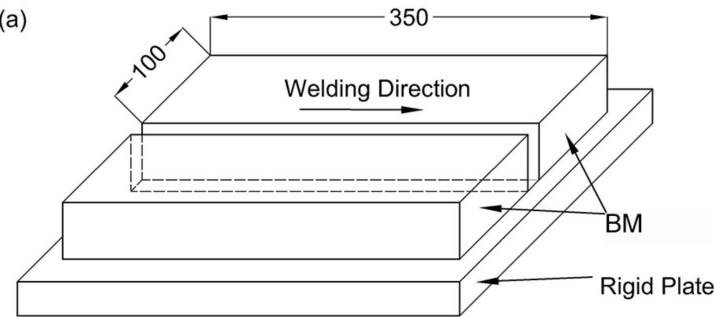

(b)

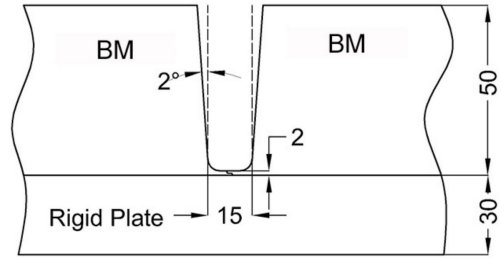

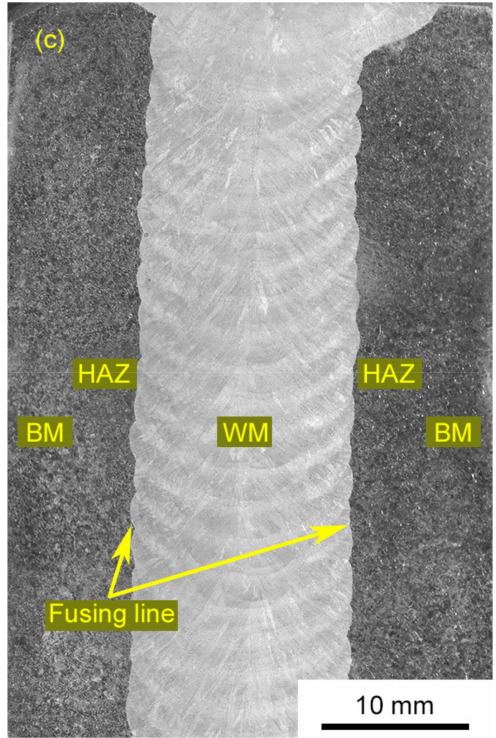

Figure 1. Schematic diagram of (a) the set-up structure and (b) groove of 617B GTAW (mm). (c) Micrograph of welded joint section (OM).

Table 1. Chemical compositions of BM and filler metal (wt \%).

\begin{tabular}{ccccccccccc}
\hline Elements & $\mathbf{C}$ & $\mathbf{C o}$ & $\mathbf{C r}$ & $\mathbf{F e}$ & $\mathbf{M o}$ & $\mathbf{T i}$ & $\mathrm{Al}$ & $\mathbf{N b}$ & $\mathbf{B}$ & $\mathbf{N i}$ \\
\hline BM & 0.052 & 12.05 & 22.38 & 0.33 & 9.02 & 0.44 & 1.03 & 0.03 & 0.0045 & Bal. \\
$\begin{array}{c}\text { Filler } \\
\text { metal }\end{array}$ & 0.07 & 11.20 & 22.50 & - & 8.90 & 0.39 & 1.27 & - & - & Bal. \\
\hline
\end{tabular}

Table 2. Welding parameters of GTAW.

\begin{tabular}{cccc}
\hline Current (A) & Voltage (V) & Welding Speed $(\mathrm{cm} / \mathbf{m i n})$ & Heat Input $(\mathbf{k J} / \mathbf{c m})$ \\
\hline 180 & 12 & $8-9$ & $16-19$ \\
\hline
\end{tabular}

As the HAZ in multi-pass welded joint is very narrow and inhomogeneous, it is difficult to investigate the effects of welding thermal cycles on the HAZ microstructure quantitatively. To solve this problem, thermal simulations were carried out on a DIL 805A dilatometer to duplicate the microstructure in HAZ. Specimens with a dimension of $10 \times 5 \times 5$ (in mm) were employed in these experiments. Considering the characteristic of multi-layer welding process, HAZ would experience more than one thermal cycle. The HAZ microstructure produced by the previous weld thermal cycle might be altered by the subsequent ones. Therefore, two types of thermal cycles were applied in thermal simulation work, as shown in Figure 2. The thermal simulations with one thermal cycle, as shown in Figure 2a, were carried out to investigate the primary HAZ microstructure produced by the first thermal cycle. These specimens were heated to a range of peak temperatures $\left(\mathrm{T}_{\mathrm{p} 1}=1200{ }^{\circ} \mathrm{C}\right.$, $1250{ }^{\circ} \mathrm{C}$, and $1300{ }^{\circ} \mathrm{C}$ ) at a rate of $100{ }^{\circ} \mathrm{C} / \mathrm{s}$, held at the peak temperature for $\mathrm{t}_{\mathrm{p} 1}=0.5 \mathrm{~s}$ and then cooled down to room temperature at a rate of $200{ }^{\circ} \mathrm{C} / \mathrm{s}$. To investigate the effect of the subsequent thermal cycle on HAZ microstructures produced by the previous one, one more thermal cycle was added, as shown in Figure $2 b$. The peak temperature $\mathrm{T}_{\mathrm{p} 2}$ of the second thermal cycle was set as $1100{ }^{\circ} \mathrm{C}$ and the holding times $t_{\mathrm{p} 2}$ were set as $1 \mathrm{~s}, 5 \mathrm{~s}, 10 \mathrm{~s}$, and $20 \mathrm{~s}$, respectively. The argon atmosphere was maintained in the thermal simulation to protect the specimens from oxidation. Two samples were processed and the metallography observed for each condition. It should be noted that, due to equipment limitations, the heating rate of $100{ }^{\circ} \mathrm{C} / \mathrm{s}$ applied in this research is much lower than that in the actual HAZ, which could reach more than $1000{ }^{\circ} \mathrm{C} / \mathrm{s}$ during GTAW welding [25]. However, the heating rate applied in our research is feasible for revealing the microstructural evolution in actual HAZ, because the same 
microstructure in actual HAZ has been obtained in thermal simulation samples. In the section No. 4 in this paper, the influence of heating rate on the microstructural evolution of HAZ will be discussed in detail.
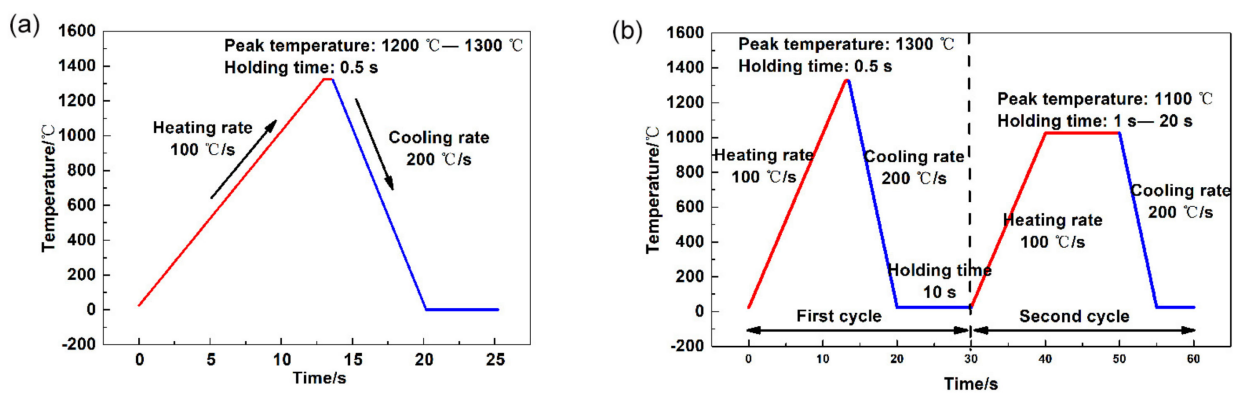

Figure 2. Temperature-time curves of thermal simulations: (a) one thermal cycle and (b) two thermal cycles.

Microstructural analysis of welded joint and simulated HAZ specimens was carried out by OM, SEM, and TEM. EDX (energy-dispersive X-ray spectrometry), used in SEM and TEM systems, was employed for chemical composition measurement. The TEM specimens were prepared by FIB (focused ion beam). SAED (selected area electron diffraction) was conducted to identify the phase type of interest. SIMS was applied to analyze the boron distribution in the alloy. These samples were mechanically polished, then etched with Kalling's reagent $(100 \mathrm{~mL}$ hydrochloric acid $+100 \mathrm{~mL}$ alcohol $+5 \mathrm{~g}$ copper chloride) for $150 \mathrm{~s}$ to reveal the microstructure for SEM and SIMS analysis.

\section{Results}

\subsection{Microstructures of the Welded Joint}

The microstructure of BM under as-received condition is shown in Figure 3. This microstructure features an austenitic matrix and many large-sized particles, as shown in Figure 3a,b. The austenitic grain size in the matrix is within the range from 30 to $300 \mu \mathrm{m}$. In Figure 3b, globular particles of about 3-10 $\mu \mathrm{m}$ are distributed along the grain boundaries discontinuously. Figure $3 \mathrm{c}$ shows the morphology and SAED pattern of these particles obtained by TEM. SAED pattern analysis suggests that these particles have an FCC structure with a lattice constant of $10.69 \AA$. The EDX results (Figure $3 \mathrm{~d}$ ) indicate that these particles are rich in $\mathrm{Cr}, \mathrm{Mo}$, and $\mathrm{C}$. Both structural and chemical analyses suggest that these particles are $\mathrm{M}_{23} \mathrm{C}_{6}$-type carbides, which is consistent with Tytko's findings [26].

The microstructure of the welded joint from HAZ to WM is shown in Figure 4a. No obvious grain growth was found in HAZ after welding. However, particles with different morphologies were observed near the fusion line, as shown in Figure $4 \mathrm{~b}$. Magnified views of these particles in HAZ are shown in Figure 4c-e. It is obvious that the particle morphologies are highly related to their distance to the fusion line, namely the different peak temperatures experienced during welding. In Figure $4 \mathrm{~b}$, the carbide in the red rectangular, which is far away from the fusion line, maintains a similar size and shape to those under as-received condition. Closer to the fusion line, a new kind of microstructure with a network shape surrounded by some fine precipitates is observed, as shown in Figure 4 d,e. 

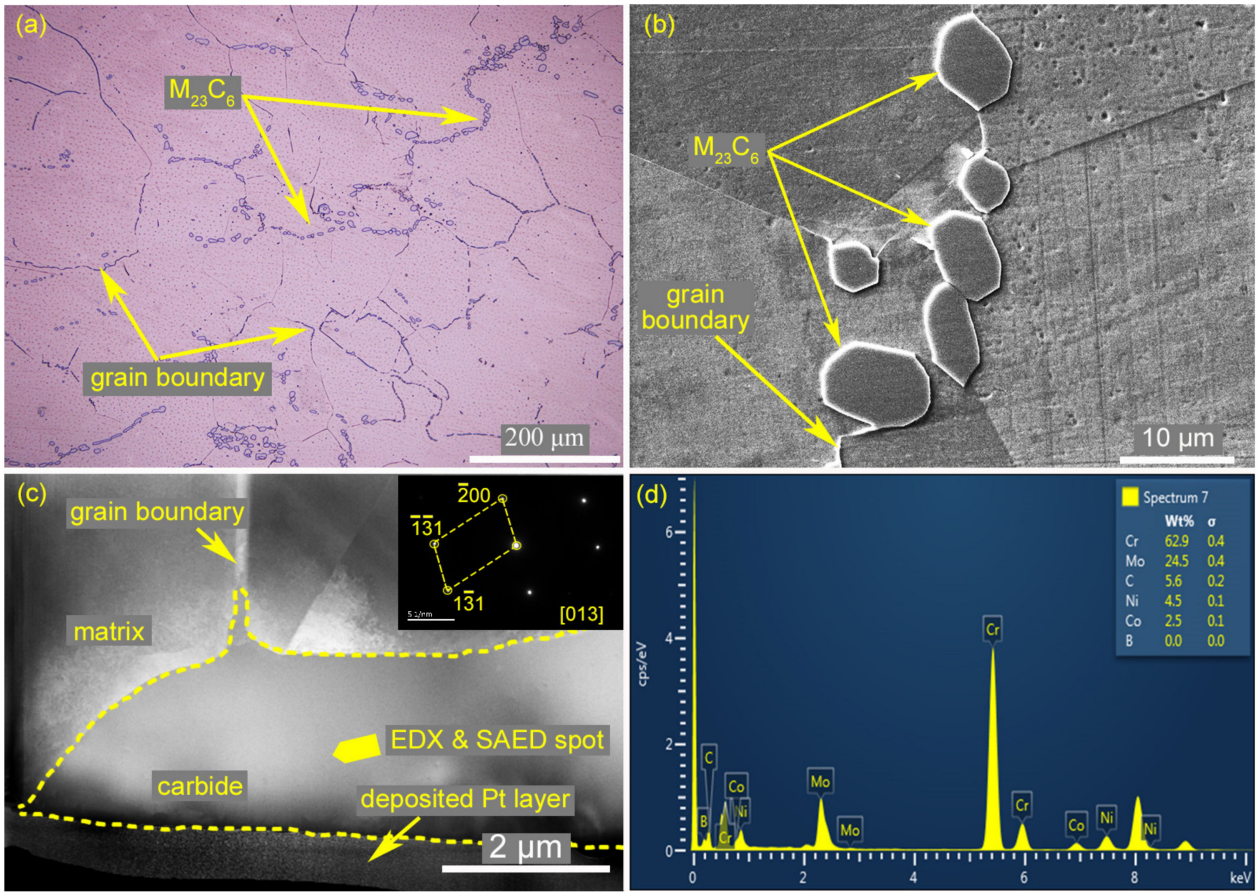

Figure 3. Microstructure of 617B BM under the as-received condition: (a) OM, (b) SEM, (c) TEM, and SAED, (d) EDX result of the carbide in (c).

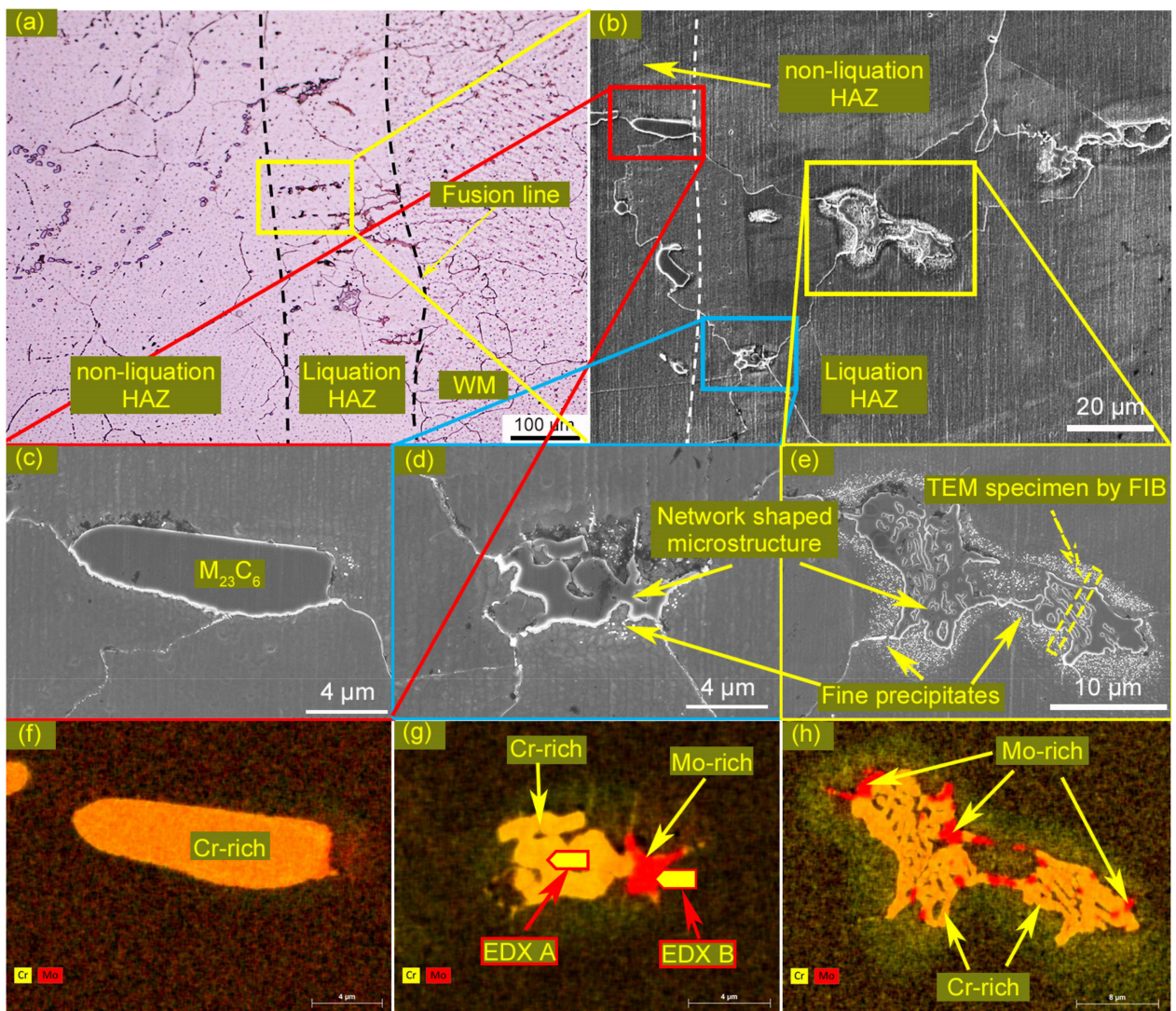

Figure 4. Microstructure of the welded joint including HAZ and WM. (a) OM; (b) is a magnified image of HAZ in (a) obtained by SEM; (c-e) are magnified zones marked by red/blue/yellow rectangles in (b) obtained by SEM, respectively; (f-h) are chemical compositional mappings of microstructures in (c-e), respectively. 
Elemental mapping analysis by EDX was employed and the main elements ( $\mathrm{Cr}$ and Mo) in these particles are shown in Figure $4 \mathrm{f}-\mathrm{h}$. It is revealed that the particle in Figure $4 \mathrm{c}$ is rich in $\mathrm{Cr}$, similar to that of $\mathrm{M}_{23} \mathrm{C}_{6}$ carbides in Figure 3d. However, the element maps in Figure $4 \mathrm{~g}$, h indicate that both $\mathrm{Cr}$ and Mo are enriched in these microstructures, implying the presence of a new microstructure composed of multiple phases. The detailed chemical compositions of the $\mathrm{Cr}$-rich phase and Mo-rich phase, marked by $\mathrm{A}$ and $\mathrm{B}$ are listed in Table 3. In addition, a Cr-rich region surrounding these microstructures can be seen in Figure 4h, different from the carbides in Figure 4f. According to the above results, it seems that the $\mathrm{M}_{23} \mathrm{C}_{6}$ carbides evolve in different manners due to the different peak temperatures that they experience. To clarify the effects of welding thermal cycles on $\mathrm{M}_{23} \mathrm{C}_{6}$ carbides' evolutionary behavior, thermal simulations with a range of peak temperatures and different numbers of cycles were conducted.

Table 3. Chemical compositions measured by EDX in SEM: the Cr-rich phase (EDX A in Figure 4g) and Mo-rich phase (EDX B in Figure 4g) (wt \%).

\begin{tabular}{cccccccc}
\hline Elements & $\mathbf{C}$ & $\mathbf{A l}$ & $\mathbf{T i}$ & $\mathbf{M o}$ & $\mathbf{C r}$ & $\mathbf{C o}$ & $\mathbf{N i}$ \\
\hline Cr-rich phase (A) & 2.26 & 0.41 & - & 24.31 & 50.03 & 5.94 & 17.04 \\
Mo-rich phase (B) & 1.51 & 0.51 & 1.67 & 46.48 & 21.26 & 7.92 & 20.70 \\
\hline
\end{tabular}

\subsection{Thermal Simulation with One Thermal Cycle}

Different distances to the fusion line mean different peak temperatures during the welding process. To clarify the effect of the peak temperatures on carbides' evolutionary behavior, three typical peak temperatures $\left(1200^{\circ} \mathrm{C}, 1250^{\circ} \mathrm{C}\right.$, and $\left.1300^{\circ} \mathrm{C}\right)$ were selected, with the thermal curves shown in Figure $2 \mathrm{a}$. Particles with different morphologies after thermal simulations were observed by SEM, as shown in Figure 5.
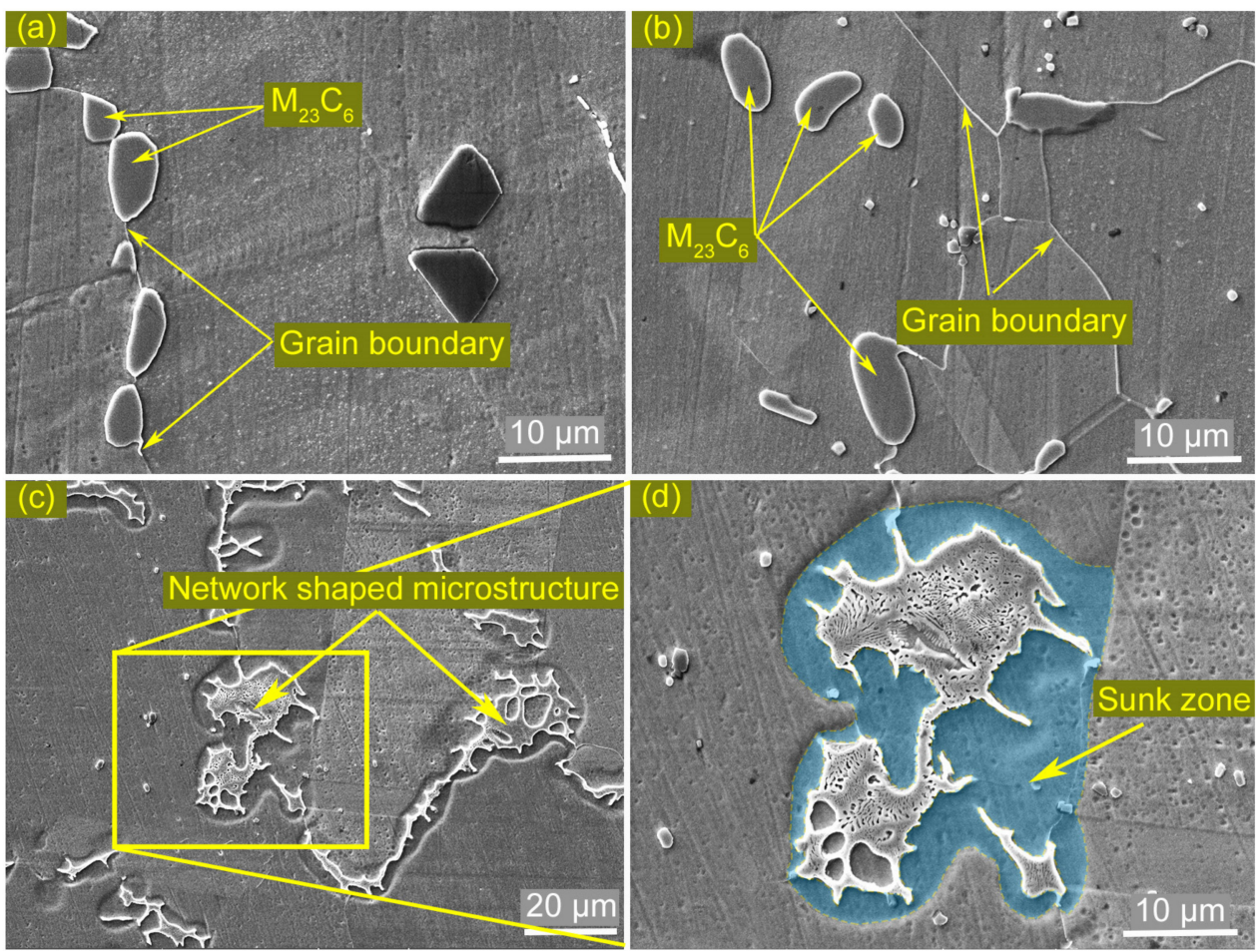

Figure 5. Microstructures observed by SEM after thermal simulation with varied peak temperatures (a) $\mathrm{T}_{\mathrm{p} 1}=1200{ }^{\circ} \mathrm{C}, \mathrm{t}_{\mathrm{p} 1}=0.5 \mathrm{~s},(\mathbf{b}) \mathrm{T}_{\mathrm{p} 1}=1250{ }^{\circ} \mathrm{C}, \mathrm{t}_{\mathrm{p} 1}=0.5 \mathrm{~s},(\mathbf{c})$ and $(\mathrm{d}) \mathrm{T}_{\mathrm{p} 1}=1300{ }^{\circ} \mathrm{C} . \mathrm{t}_{\mathrm{p} 1}=0.5 \mathrm{~s}$.

There is no discernible change in the simulated specimens with $\mathrm{T}_{\mathrm{p} 1}=1200{ }^{\circ} \mathrm{C}$ and $1250{ }^{\circ} \mathrm{C}$ compared with the carbides under as-received condition, as shown in Figure $5 \mathrm{a}, \mathrm{b}$. As $\mathrm{T}_{\mathrm{p} 1}$ reaches 
$1300{ }^{\circ} \mathrm{C}$, the globular $\mathrm{M}_{23} \mathrm{C}_{6}$ is replaced by network-shaped microstructures, as shown in Figure $5 \mathrm{c}$. A magnified image of network-shaped microstructure is shown in Figure $5 \mathrm{~d}$; its morphology is similar to that presented in Figure 4e. The thermal simulation results indicate that the temperature at which the globular $\mathrm{M}_{23} \mathrm{C}_{6}$ transforms into network-shaped microstructures is in the range from $1250{ }^{\circ} \mathrm{C}$ to $1300{ }^{\circ} \mathrm{C}$. However, it should be noted that there are differences between the thermal simulated microstructure and that of the real welded joint: in the simulated specimen no fine precipitates are observed surrounding the network-shaped microstructure, while fine precipitates are present in the real welded joint (Figure 4e). In addition, a sunken zone caused by etching was observed surrounding the network-shaped microstructures, as shown in Figure $5 c, d$, indicating that the chemical composition was altered in this region.

\subsection{Thermal Simulation with Two Thermal Cycles}

As mentioned above, no fine precipitate has been found around the network-shaped microstructure in the simulated specimens experiencing only one thermal cycle. The presence of fine precipitates might be related to the multiple thermal cycles that the real HAZ is subjected to, which means that thermal cycles of the subsequent layers might temper the HAZ formed by previous ones. To clarify the effect of subsequent thermal cycles on the presence of fine precipitates, thermal simulations with two thermal cycles (as shown in Figure 2b) were conducted and the typical microstructures produced by the thermal simulations are shown in Figure 6.
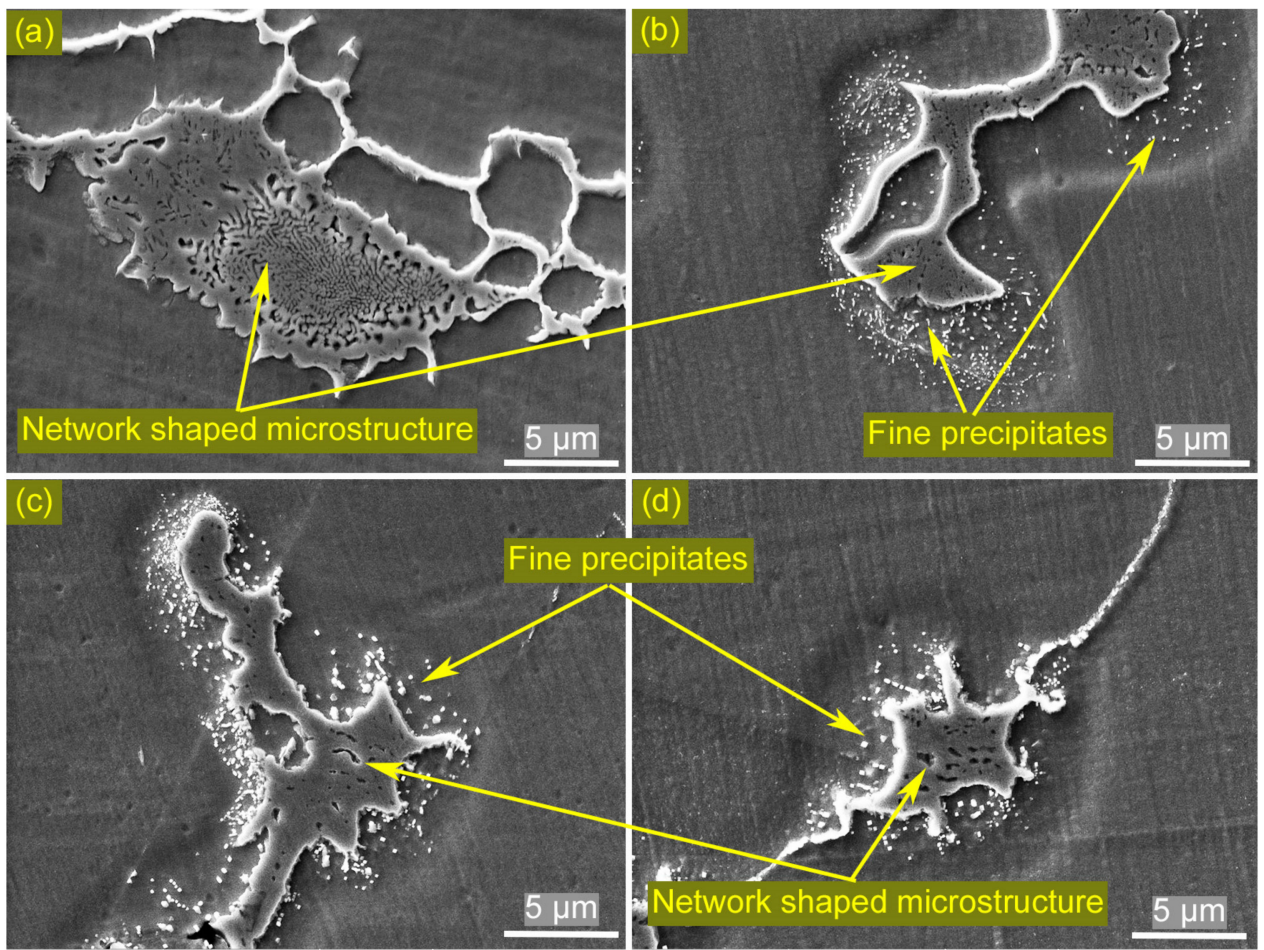

Figure 6. Microstructure images obtained by SEM after thermal simulations with two thermal cycles. The peak temperature of the second thermal cycle $\mathrm{T}_{\mathrm{p} 2}$ was $1100{ }^{\circ} \mathrm{C}$ and the holding time $t_{\mathrm{p} 2}$ were (a) 1 s, (b) $5 \mathrm{~s}$, (c) $10 \mathrm{~s}$, and (d) $20 \mathrm{~s}$.

It is evident that fine precipitates form after undergoing two thermal cycles when the holding time of the second cycle $t_{\mathrm{p} 2}$ is $5 \mathrm{~s}$ or longer, as shown in Figure $6 \mathrm{~b}-\mathrm{d}$. When $t_{\mathrm{p} 2}$ is $1 \mathrm{~s}$, there is no fine precipitate observed (Figure 6a), which might be attributed to the insufficient holding time for the precipitates to form. In addition, by comparing Figure $6 b, c$, it is obvious that the fine precipitates of $t_{\mathrm{p} 2}=10 \mathrm{~s}$ are much coarser than those of $t_{\mathrm{p} 2}=5 \mathrm{~s}$; this might be ascribed to the longer time for the forming atoms to diffuse to the precipitates. 


\subsection{Identification of the Eutectic Microstructure in HAZ}

The TEM specimen was prepared using FIB, as shown by the dotted rectangle indicated in Figure 4e. The specimen contained network-shaped microstructure with fine precipitates around it. Crystal and composition information were obtained by SAED and EDX, respectively.

Figure 7a shows the morphology of the network-shaped microstructure by TEM and Figure 7b presents the magnified image of the fine precipitates. Table 4 lists the chemical compositions of these phases. It is clearly demonstrated that the network-shaped microstructure is composed of three constituents with distinct morphologies, which are exhibited in the black, gray, and white zones marked by C, D, and E, respectively. The intervals between the black or gray zones are filled with the white ones, which means that the black/gray zones and the white zones appear alternatively, similar to the eutectic microstructures. SAED and EDX results confirm that the black, gray, and white zones are $\mathrm{M}_{23} \mathrm{C} 6, \mathrm{M}_{6} \mathrm{C}$, and $\gamma$ (matrix), respectively. It is noted that $\mathrm{M}_{6} \mathrm{C}$ has a similar crystal structure to $\mathrm{M}_{23} \mathrm{C}_{6}$, but a higher Mo concentration [27-29]. In Figure $4 \mathrm{~g}$ and $\mathrm{h}$, the red zones are supposed to be $\mathrm{M}_{6} \mathrm{C}$ due to Mo enrichment, and the $\mathrm{Cr}$-enriched zones are $\mathrm{M}_{23} \mathrm{C}_{6}$ phase. Fine precipitates around the network-shaped microstructure shown in Figure $4 \mathrm{~d}$,e are also observed by TEM and present as a cuboidal shape with a size of about $200 \mathrm{~nm}$, marked by $\mathrm{F}$ in Figure $7 \mathrm{~b}$. The fine precipitates are also identified to be $\mathrm{M}_{23} \mathrm{C}_{6}$-type carbides by SAED, as shown in Figure $7 \mathrm{f}$.

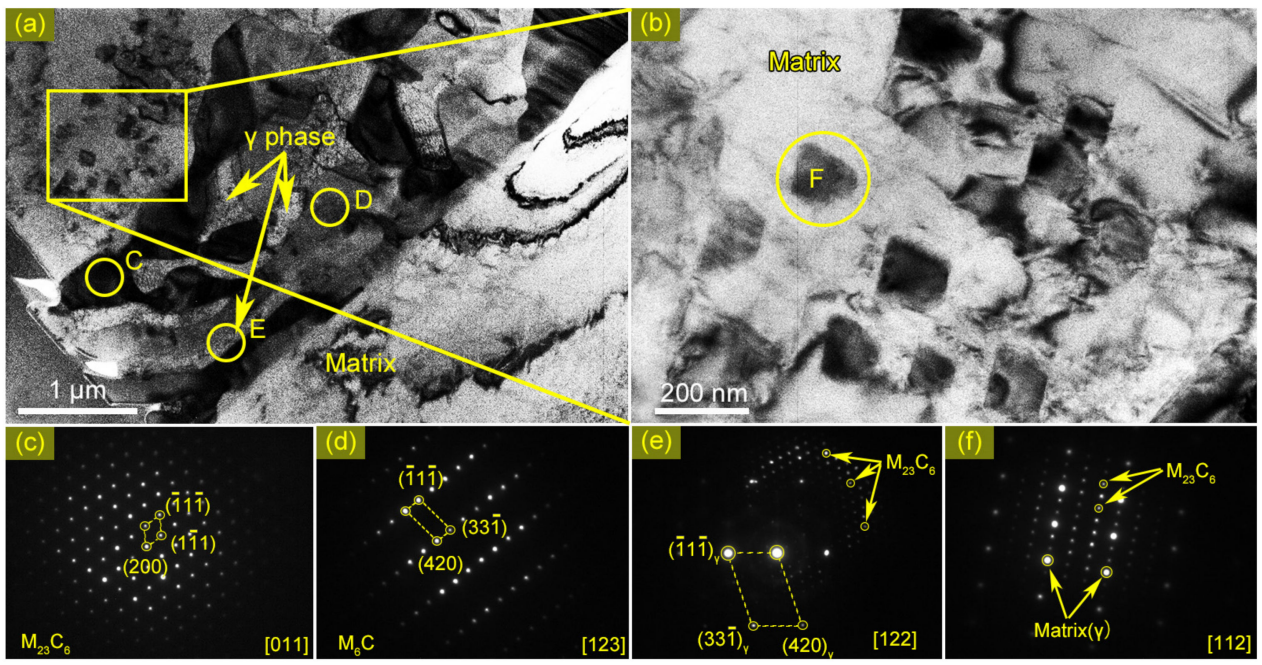

Figure 7. TEM images of network-shaped microstructure: (a) bright field; (b) bright-field image of fine precipitates; (c)-(e) are SAED patterns of zones C, D, and E marked in (a), respectively; (f) SAED pattern of fine precipitates marked by $\mathrm{F}$ in (b).

Table 4. Chemical compositions measured by EDX in TEM: $\mathrm{M}_{23} \mathrm{C}_{6}(\mathrm{C}$ in Figure $7 \mathrm{a})$ and $\mathrm{M}_{6} \mathrm{C}$ (D in Figure 7a) in a network-shaped structure and $\mathrm{M}_{23} \mathrm{C}_{6}$ in fine precipitates ( $\mathrm{F}$ in Figure 7a) (wt \%).

\begin{tabular}{cccccccc}
\hline Elements & $\mathbf{C}$ & $\mathbf{A l}$ & $\mathbf{T i}$ & $\mathbf{M o}$ & $\mathbf{C r}$ & $\mathbf{C o}$ & $\mathbf{N i}$ \\
\hline $\mathrm{M}_{23} \mathrm{C}_{6}$ in network-shaped \\
$\begin{array}{c}\text { structure } \\
\mathrm{M}_{6} \mathrm{C} \text { in network-shaped } \\
\begin{array}{c}\text { structure } \\
\mathrm{M}_{23} \mathrm{C}_{6} \text { in fine precipitates }\end{array}\end{array}$ & 3.2 & 0.3 & - & 21.7 & 38.4 & 6.3 & 21.1 \\
\hline
\end{tabular}

\section{Discussion}

Based on the observation of microstructures in real welded joints and simulated HAZ specimens, it is confirmed that the morphology of precipitates in HAZ is altered by peak temperatures and thermal cycle numbers. Precipitates adjacent to the fusion line (Figure 4e) and in specimens subjected to the peak temperature of $1300^{\circ} \mathrm{C}$ (Figure 5d) present a network shape, similar to the eutectic microstructure, 
which is presumably related to the liquation phenomenon and eutectic reaction. Further, welding thermal simulations confirm that the eutectic microstructure is transformed from coarse precipitates along grain boundaries in $\mathrm{BM}$, which are identified as $\mathrm{M}_{23} \mathrm{C}_{6}$ carbides by TEM.

The liquation of $\mathrm{M}_{23} \mathrm{C}_{6}$ carbides during the rapid heating process provided by welding can be explained by the constitutional liquation mechanism. The mechanism of constitutional liquation of $\mathrm{M}_{23} \mathrm{C}_{6}$ carbides in the present work can be illustrated as follows.

Figure 8 is a schematic binary phase diagram between $\gamma$ (matrix) and $\mathrm{M}_{23} \mathrm{C}_{6}$ carbides and Figure 9 is a schematic illustration of $\mathrm{M}_{23} \mathrm{C}_{6}$ evolutionary behavior during welding thermal simulation. It is obvious that the chemical composition of the as-received BM, $\mathrm{C}_{0}$, is located in the two-phase region due to the coexistence of $\gamma$ and $\mathrm{M}_{23} \mathrm{C}_{6}$. It is well known that under equilibrium conditions, phase transformation will take place along the blue dotted vertical line that goes through $\mathrm{C}_{0}$ by elevating the temperature. When the temperature reaches $1300{ }^{\circ} \mathrm{C}$, there is no liquid. However, for the non-equilibrium heating process of welding, the phase transformation would be different. Rapid heating permits insufficient time for solute atoms such as $\mathrm{Cr}$ released from the partially dissolved $\mathrm{M}_{23} \mathrm{C}_{6}$ carbides to diffuse into the surrounding matrix ( $\gamma$ phase). In this way, the surrounding matrix was $\mathrm{Cr}$ saturated, causing the chemical composition of the adjacent matrix to change along the solvus from points 1 to 3 . Once the chemical composition of adjacent matrix reaches point 3 , the eutectic reaction $\gamma+\mathrm{M}_{23} \mathrm{C}_{6} \rightarrow$ liquid will occur between the matrix and adjacent incompletely dissolved $\mathrm{M}_{23} \mathrm{C}_{6}$ carbides. A small amount of liquid forms by eutectic reaction, as shown in Figure 9a-c. To simplify matters, we can move the blue dotted line to the red dotted line, which will not change the nature of the problem. It is obvious that as the temperature increases from eutectic temperature to $1300{ }^{\circ} \mathrm{C}$, the amount of liquid increases (Figure 9d), and the chemical composition of $\gamma$ varies along solidus from point 3 to 4 . At the same time as the liquid phase is formed, the migration of grain boundary also occurs in HAZ. Some migrated grain boundaries will meet the liquid phase, allowing the liquid phase to penetrate the grain boundaries [30].

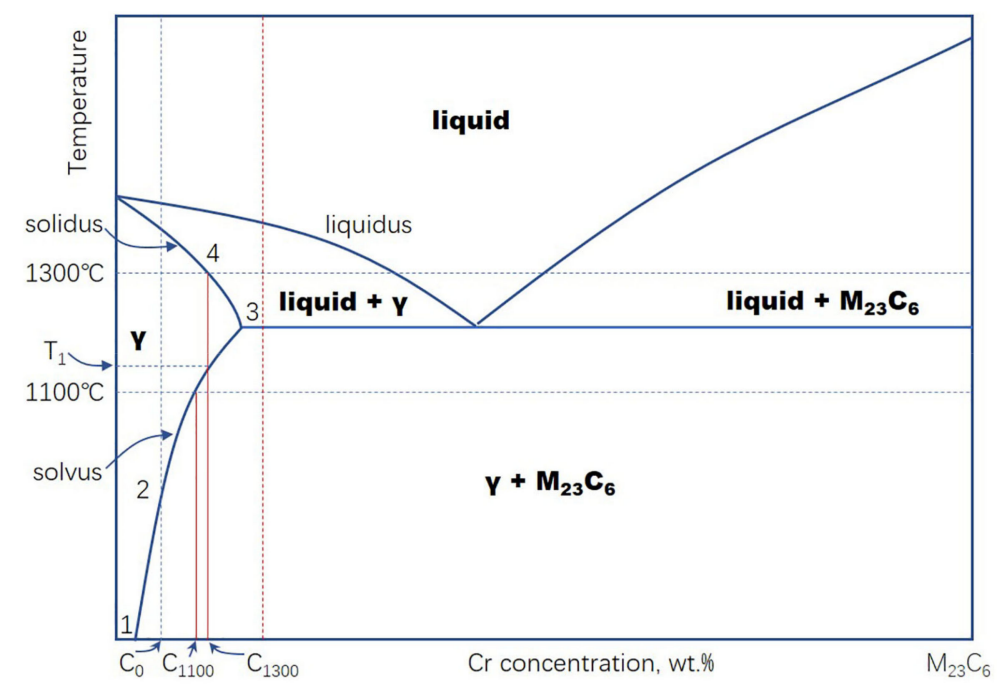

Figure 8. A schematic binary phase diagram between $\gamma$ phase and $\mathrm{M}_{23} \mathrm{C}_{6}$ carbides. 


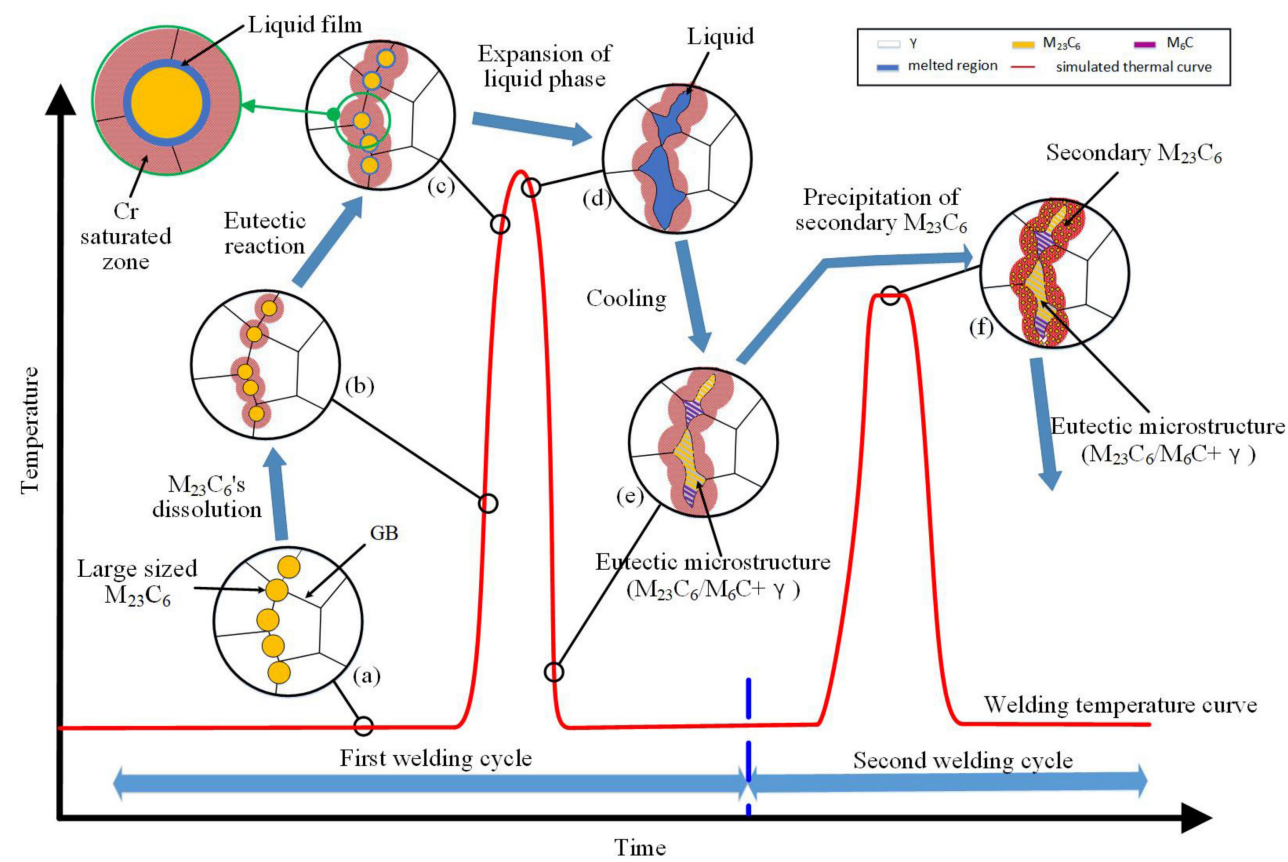

Figure 9. Schematic illustration of $\mathrm{M}_{23} \mathrm{C}_{6}$ evolutionary behavior during welding thermal simulation.

The liquation process mentioned above is highly related to the heating rate. If the heating rate is slow enough, the $\mathrm{M}_{23} \mathrm{C}_{6}$ carbides will be dissolved completely in the matrix before the temperature reaches the eutectic point. If the heating rate is rapid, insufficient diffusion of solute atoms will result in incomplete dissolution of $\mathrm{M}_{23} \mathrm{C}_{6}$ carbides, leading to a eutectic reaction between the survived $\mathrm{M}_{23} \mathrm{C}_{6}$ carbides and the matrix when the temperature reaches the eutectic point. The same network-shaped microstructures in HAZ are observed in the thermal simulation samples (shown in Figure $5 \mathrm{c}, \mathrm{d}$ and Figure 6), meaning a similar liquation process to that in HAZ occurs in these samples. The difference in heating rate does not change the nature of the liquation process that occurs in HAZ and the thermal simulations, but may affect the degree of liquation, which is reflected in the volume of the liquid phase generated. In addition, the contribution of boron to HAZ liquation cannot be ignored. Figure 10 shows the distribution maps of $\mathrm{Cr}, \mathrm{B}$, and $\mathrm{C}$ under as-received condition. It can be seen that boron is enriched in $\mathrm{M}_{23} \mathrm{C}_{6}$ carbides (Figure 10c). Boron promotes HAZ liquation by two mechanisms. First, boron in $\mathrm{M}_{23} \mathrm{C}_{6}$ carbides can lower the liquation temperature [31-33], making liquation more likely to occur during the heating process. Moreover, boron released from dissolved $\mathrm{M}_{23} \mathrm{C}_{6}$ carbides can lower the solid/phase surface energy, promoting the liquid phase to penetrate grain boundaries [16,30].

After holding at a peak of $1300^{\circ} \mathrm{C}$, the temperature starts to decrease, and some liquid transforms into austenite, of which the chemical composition varies along solidus from point 4 to 3 . Once the temperature reaches the eutectic line, a eutectic reaction occurs, by which the residual liquid transforms into eutectic constituents, namely $\gamma$ and $\mathrm{M}_{23} \mathrm{C}_{6}$ or $\mathrm{M}_{6} \mathrm{C}$ (depending on the relative concentration of Mo and $\mathrm{Cr}$ ) simultaneously, as shown in Figure $9 \mathrm{e}$.

It should be noted that the austenite that forms before eutectic reaction will be $\mathrm{Cr}$ supersaturated once the temperature decreases below T1, as shown in Figure 8, due to the rapid cooling rate not providing enough time for $\mathrm{Cr}$ atoms to diffuse to form carbides. The zone of supersaturated austenite corresponds to the sunk zone surrounding eutectic microstructure, as shown in Figure $5 \mathrm{~d}$. If the specimen is exposed to a secondary thermal cycle, there will be a chance for the supersaturated $\mathrm{Cr}$ atoms to precipitate as carbides. In the present thermal simulation, the peak temperature of the second thermal cycle is set as $1100^{\circ} \mathrm{C}$, at which point it is assumed that the maximum solid solubility of $\mathrm{Cr}$ $\left(\mathrm{C}_{1100}\right)$ is lower than that at $1300^{\circ} \mathrm{C}\left(\mathrm{C}_{1300}\right)$, as shown in Figure 8. At $1100{ }^{\circ} \mathrm{C}$, combined with proper holding time ( $\geq 5 \mathrm{~s})$, fine carbides $\left(\mathrm{M}_{23} \mathrm{C}_{6}\right)$ will precipitate in the supersaturated zone (Figure $9 \mathrm{f}$ ); that is 
why there is such a large number of fine precipitates around the eutectic microstructure in the real multilayer welded joints and simulated specimens subjected to two thermal cycles.
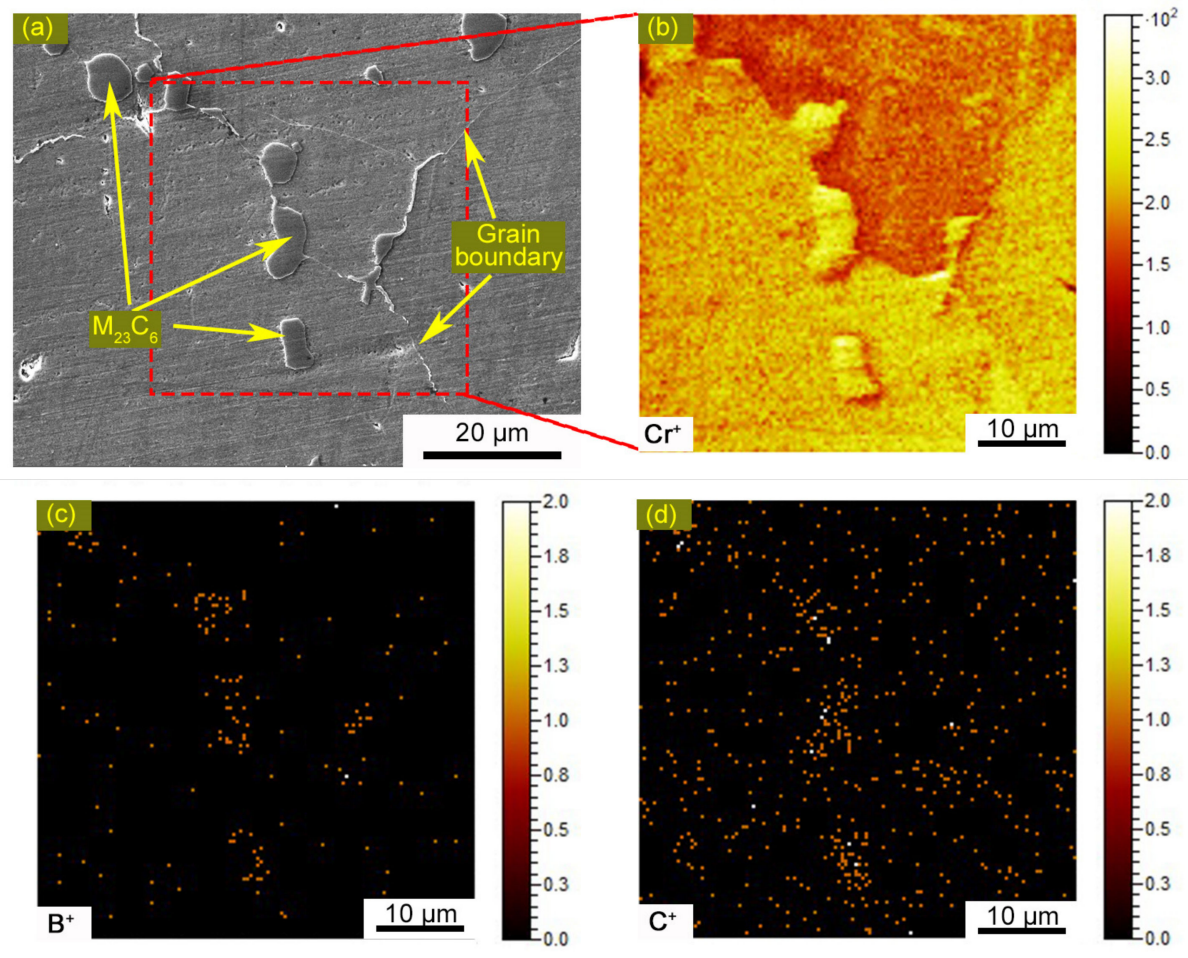

Figure 10. (a) SEM micrograph of BM and SIMS micrographs of $(\mathbf{b}) \mathrm{Cr}^{+}$, (c) $\mathrm{B}^{+}$and $(\mathbf{d}) \mathrm{C}^{+}$distribution in (a).

Although constitutional liquation of $\mathrm{M}_{23} \mathrm{C}_{6}$ carbides occurs in $\mathrm{HAZ}$ during welding heating process, no cracking has been found in welded joints. Liquation cracking occurs, combined with the presence of liquid phase on grain boundary and the thermal tensile stress [34]. The liquid film weakens grain boundary adhesive strength, and liquation cracking forms when the thermal tensile stress exceeds the grain boundary adhesive strength. The relationship between the tensile stress $\sigma$ required to separate the liquid filled grain boundary and the thickness of the liquid film $h$ is given by Miller et al. [35]: $\sigma=\gamma_{\mathrm{SL}} / 2 \mathrm{~h}$, while $\gamma_{\mathrm{SL}}$ is the solid/phase surface energy. According to this relationship, the weakening effect of the liquid film on grain boundary will be stronger with $\mathrm{h}$ increasing. As stated earlier, the liquid film is produced by a eutectic reaction of partially dissolved $\mathrm{M}_{23} \mathrm{C}_{6}$ carbides and the matrix, which means the thickness of liquid film is directly related to the dimension of the $\mathrm{M}_{23} \mathrm{C}_{6}$ carbides. It can be inferred that liquation cracking could be avoided by controlling the size of $\mathrm{M}_{23} \mathrm{C}_{6}$ carbides and the welding heating input. In the present research, no liquation cracking found in the welded joint indicates that GTAW is a suitable method to join alloy 617B.

\section{Conclusions}

In the present study, the mechanism for HAZ liquation in the alloy 617B welded joint was investigated. The following four conclusions can be drawn according to the current results.

1. Liquation occurs in HAZ close to the fusion line of the alloy 617B GTAW welded joint. The morphology and the chemical composition of particles in HAZ are altered because of the liquation phenomenon. No liquation cracking has been found in HAZ under the current welding conditions.

2. Constitutional liquation of large $\mathrm{M}_{23} \mathrm{C}_{6}$ carbides during a rapid heating process is responsible for HAZ liquation of the $617 \mathrm{~B}$ welded joint. Rapid heating means the solute atoms $\mathrm{Cr}$ and Mo released from partially dissolved $\mathrm{M}_{23} \mathrm{C}_{6}$ carbides do not have enough time to diffuse into the matrix, resulting in eutectic reaction $\mathrm{M}_{23} \mathrm{C}_{6}+\gamma \rightarrow$ liquid in the temperature range from $1250{ }^{\circ} \mathrm{C}$ to $1300{ }^{\circ} \mathrm{C}$. The liquid 
phase transforms into $\gamma$ and carbides $\left(\mathrm{M}_{23} \mathrm{C}_{6}\right.$ or $\left.\mathrm{M}_{6} \mathrm{C}\right)$ simultaneously, namely a eutectic microstructure, during the subsequent cooling process.

3. The presence of the fine precipitates is related to the multiple thermal cycles that HAZ is subjected to in real welded joints. The first thermal cycle with higher peak temperatures leaves the zone around the eutectic microstructure supersaturated in $\mathrm{Cr}$ after cooling, and the second thermal cycle with a lower peak temperature provides a suitable combination of temperature and time for $\mathrm{Cr}$ to precipitate from the matrix.

4. Boron in alloy $617 \mathrm{~B}$ is found to be enriched in $\mathrm{M}_{23} \mathrm{C}_{6}$ carbides. Boron is expected to promote $\mathrm{HAZ}$ liquation by lowering the liquation temperature of $\mathrm{M}_{23} \mathrm{C}_{6}$ carbides and promoting the liquid phase to penetrate grain boundaries.

Author Contributions: Conceptualization: S.L., K.L., and Z.C.; methodology: S.L., M.H., and Y.W.; resources: Z.C. and J.P.; writing-original draft preparation: S.L.; writing-review and editing: K.L. and Z.C.; project administration: K.L., Z.C., and J.P. All authors have read and agreed to the published version of the manuscript.

Funding: This research was funded by the National Natural Foundation of China (Project Nos. 51775300 and NO. 51901113) and the Tribology Science Fund of the State Key Laboratory of Tribology in Tsinghua University (Project No. SKLT2015A02).

Acknowledgments: The authors are grateful for Anli Lu and Jialie Ren, who provided important advice on the present work. Rong Wang and Wenyan Yang, Senior Engineers in the State Key Laboratory of Tribology, helped us finish the SEM and FIB experiments, for which we are grateful.

Conflicts of Interest: The authors declare no conflict of interest.

\section{References}

1. Viswanathan, R.; Henry, J.F.; Tanzosh, J.; Stanko, G.; Shingledecker, J.; Vitalis, B.; Purgert, R.U.S. Program on materials technology for ultra-supercritical coal power plants. J. Mater. Eng. Perform. 2005, 14, 281-292. [CrossRef]

2. Klöwer, J.; Husemann, R.U.; Bader, M. Development of nickel alloys based on alloy 617 for components in $700{ }^{\circ} \mathrm{C}$ power plants. Procedia Eng. 2013, 55, 226-231. [CrossRef]

3. Ren, W.J.; Lu, F.G.; Yang, R.J.; Liu, X.; Li, Z.G. Liquation cracking in fiber laser welded joints of inconel 617. J. Mater. Process. Technol. 2015, 226, 214-220. [CrossRef]

4. Ojo, O.A.; Richards, N.L.; Chaturvedi, M.C. Contribution of constitutional liquation of gamma prime precipitate to weld HAZ cracking of cast Inconel 738 superalloy. Scr. Mater. 2004, 50, 641-646. [CrossRef]

5. Qian, M.; Lippold, J.C. The effect of annealing twin-generated special grain boundaries on HAZ liquation cracking of nickel-base superalloys. Acta Mater. 2003, 51, 3351-3361. [CrossRef]

6. Cieslak, M.J.; Stephens, J.J.; Carr, M.J. A study of the weldability and weld related microstructure of cabot alloy 214. Metall. Trans. A 1988, 19, 657-667. [CrossRef]

7. Cieslak, M.; Headley, T.; Romig, A. The welding metallurgy of HASTELLOY alloys C-4, C-22, and C-276. Metall. Trans. A 1986, 17, 2035-2047. [CrossRef]

8. Taheri, M.; Halvaee, A.; Kashani-Bozorg, S.F. Effect of Nd: YAG pulsed-laser welding parameters on microstructure and mechanical properties of GTD-111 superalloy joint. Mater. Res. Express 2019, 6, 1-15. [CrossRef]

9. Zhan, X.; Li, D.; Li, Y.; Lu, S. The influence of niobium on the plastic deformation behaviors of 310s austenitic stainless steel weld metals at different temperatures. Mater. Sci. and Eng. A-Struct. Mater. Prop. Microstruct. Process. 2019, 743, 648-655. [CrossRef]

10. Robino, C.; Cieslak, J. Solidification and welding metallurgy of thermo-span alloy. Sci. Technol. Weld. Join. 1997, 2, 220-230. [CrossRef]

11. Lippold, J. An investigation of weld cracking in alloy 800. Weld. J. 1983, 63, 91-103.

12. Lippold, J.; Baeslack, W.; Varol, I. Heat-affected zone liquation cracking in austenitic and duplex stainless steels. Weld. J. (USA) 1988, 71, 1-14.

13. Klöwer, J. Alloy 617 and derivatives. In Materials for Ultra-Supercritical and Advanced Ultra-Supercritical Power Plants; Woodhead Publishing: Cambridge, UK, 2017; pp. 547-570. 
14. Vishwakarma, K.R.; Chaturvedi, M.C. Effect of boron and phosphorus on HAZ microfissuring of Allvac 718 Plus superalloy. Mater. Sci. Technol. 2009, 25, 351-360. [CrossRef]

15. Van, G.T.; Carron, D.; Le Masson, P.; Robin, V.; Andrieu, A.; Stodolna, J. Effect of boron content on hot ductility and hot cracking susceptibility in $316 \mathrm{~L}$ austenitic stainless steel for welding components. J. Mater. Eng. Perform. 2018, 27, 5114-5123. [CrossRef]

16. Li, Q.; Lin, X.; Wang, X.; Yang, H.; Song, M.; Huang, W. Research on the grain boundary liquation mechanism in heat affected zones of laser forming repaired K465 nickel-based superalloy. Metals 2016, 6, 64. [CrossRef]

17. Pepe, J. Effects of constitutional liquation in 18-Ni maraging steel weldments. Weld. J. 1967, 46, 411-422.

18. Duvall, D. Further heat-affected-zone studies in heat-resistant nickel alloys. Weld. J. 1967, 46, $423-432$.

19. Owczarski, W.; Duvall, D.; Sullivan, C. A model for heat affected zone cracking in nickel-based alloys. Weld. J. 1966, 45, 145.

20. Thompson, R. The relationship between grain size and microfissuring in alloy 718. Weld. J. 1985, 64, 91s-96s.

21. Baeslack, W.A.; Nelson, D. Morphology of weld heat-affected zone liquation in cast alloy 718. Metallography 1986, 19, 371-379. [CrossRef]

22. Phuraya, N.; Phung-On, I.; Terasaki, H.; Komizo, Y. Direct observation of liquation in Ni-base superalloy by using confocal laser scanning microscopy. Key Eng. Mater. 2015, 658, 36-41. [CrossRef]

23. Xu, H.; Liu, W.; Lu, F.; Wang, P.; Ding, Y. Evolution of carbides and its characterization in HAZ during NG-TIG welding of Alloy 617B. Mater. Charact. 2017, 130, 270-277. [CrossRef]

24. Fink, C.; Zinke, M. Welding of nickel-based alloy 617 using modified dip arc processes. Weld. World 2013, 57, 323-333. [CrossRef]

25. Kou, S. Welding Metallurgy; John Wiley \& Sons: Hoboken, NJ, USA, 2003; pp. 55-56.

26. Tytko, D.; Choi, P.-P.; Klöwer, J.; Kostka, A.; Inden, G.; Raabe, D. Microstructural evolution of a Ni-based superalloy (617B) at $700 \mathrm{C}$ studied by electron microscopy and atom probe tomography. Acta Mater. 2012, 60, 1731-1740. [CrossRef]

27. Jo, T.S.; Lim, J.H.; Do Kim, Y. Dissociation of Cr-rich $\mathrm{M}_{23} \mathrm{C}_{6}$ carbide in alloy 617 by severe plastic deformation. J. Nucl. Mater. 2010, 406, 360-364. [CrossRef]

28. Inoue, A.; Masumoto, T. Carbide reactions $\left(\mathrm{M}_{3} \mathrm{C} \rightarrow \mathrm{M}_{7} \mathrm{C}_{3} \rightarrow \mathrm{M}_{23} \mathrm{C}_{6} \rightarrow \mathrm{M}_{6} \mathrm{C}\right)$ during tempering of rapidly solidified high carbon Cr-W and Cr-Mo steels. Metall. Trans. A 1980, 11, 739-747. [CrossRef]

29. Kuo, K.; Jia, C. Crystallography of $\mathrm{M}_{23} \mathrm{C}_{6}$ and $\mathrm{M}_{6} \mathrm{C}$ precipitated in a low alloy steel. Acta Metall. 1985, 33, 991-996. [CrossRef]

30. Chen, W.; Chaturvedi, M.C.; Richards, N.L. Effect of boron segregation at grain boundaries on heat-affected zone cracking in wrought INCONEL 718. Metall. Mater. Trans. A 2001, 32, 931-939. [CrossRef]

31. Huang, X.; Chaturvedi, M.C.; Richards, N.L.; Jackman, J. The effect of grain boundary segregation of boron in cast alloy 718 on HAZ microfissuring-A SIMS analysis. Acta Mater. 1997, 45, 3095-3107. [CrossRef]

32. Guo, H.; Chaturvedi, M.C.; Richards, N.L. Effect of boron concentration and grain size on weld heat affected zone microfissuring in Inconel 718 base superalloys. Sci. Technol. Weld. Join. 2013, 4, 257-264. [CrossRef]

33. Ojo, O.A. Intergranular liquation cracking in heat affected zone of a welded nickel based superalloy in as cast condition. Mater. Sci. Technol. 2007, 23, 1149-1155. [CrossRef]

34. Böllinghaus, T.; Herold, H. Hot Cracking Phenomena in Welds; Springer: Berlin/Heidelberg, Germany, 2005.

35. Miller, W.A.; Chadwick, G.A. On the magnitude of the solid/liquid interfacial energy of pure metals and its relation to grain boundary melting. Acta Metall. 1967, 15, 607-614. [CrossRef]

(C) 2020 by the authors. Licensee MDPI, Basel, Switzerland. This article is an open access article distributed under the terms and conditions of the Creative Commons Attribution (CC BY) license (http://creativecommons.org/licenses/by/4.0/). 